\title{
The Efficacy of Botulinum Toxin in Patients with Cervicogenic Headache: a Placebo-Controlled Clinical Trial
}

\author{
Ömer Karadaş ${ }^{1}$, Bilgin Öztürk ${ }^{2}$, Ümit Hıdır Ulaş², Yaşar Kütükçü², Zeki Odabaşı \\ ${ }^{1}$ Department of Neurology, Erzincan Military Hospital, Erzincan, Turkey \\ ${ }^{2}$ Department of Neurology, Gülhane Military Medical Academy, Ankara, Turkey
}

\begin{abstract}
Objective: Botulinum toxin type-A (BoNTA) has been considered a treatment option for $\mathrm{CH}$. The aim of this study was to assess the effectiveness of BoNTA treatment in patients with medically resistant $\mathrm{CH}$.

Materials and Methods: Forty patients with $\mathrm{CH}$ were included in the study. Patients in the BoNTA group ( $\mathrm{n}=20$ ) were administered $10 \mathrm{U}$ of BoNTA bilaterally to the frontal muscles, $20 U$ to the temporal muscles, $15 U$ to the semispinalis capitis, $15 \cup$ to the splenius capitis, and $15 \cup$ to the trapezius muscles (total: $150 \mathrm{U}$ ). Patients in the placebo group $(n=20)$ received $0.2 \mathrm{~mL}$ of saline administrated to the same sites. All participations were evaluated 6 and 12 weeks after treatment; side effects, the number of painful days, severity (by visual analogue scale, VAS) and frequency of pain were evaluated.
\end{abstract}

Results: In the BoNTA group, the severity and frequency of pain 6 and 12 weeks post treatment were significantly lower than pre-treatment levels $(p<0.05)$. At 12 weeks post treatment, the severity and frequency of pain in the BoNTA group were lower than in the placebo group ( $\mathrm{p}<0.05)$.

Conclusion: The findings suggest that BoNTA was an effective treatment for $\mathrm{CH}$.

Key Words: Cervicogenic headache, Botulinum toxin A

\section{Introduction}

Cervicogenic headache $(\mathrm{CH})$ was first reported by Sjaastad in 1983 (1). Fredriksen et al. presented a more detailed description in a patient diagnosed as $\mathrm{CH}$ in 1987 (2). $\mathrm{CH}$ was added as a headache disorder in the International Headache Society Classification published in 2004 (3). CH may be due to many factors associated with the back of the head and neck. Lesions that affect nerves, ganglia, nerve roots, vertebrae, joints, the periosteum, muscles, and ligaments may be etiological in $\mathrm{CH}$ (4-7).

The reported prevalence of $\mathrm{CH}$ varies. For example, the prevalence of $\mathrm{CH}$ in migraine patients was $0 \%$, versus $80 \%$ in patients with only headache $(8,9)$. In the general population, the prevalence of $\mathrm{CH}$ is between $0.4 \%$ and $2.5 \%$, and between $15 \%$ and $20 \%$ in patients with headache (10-14). Shah and $\mathrm{Nafee}$ reported that $20.9 \%$ of $\mathrm{CH}$ patients were male and $79.1 \%$ were female (15). Traumatic and degenerative changes increase the incidence of $\mathrm{CH}$ (16).

$\mathrm{CH}$ is unilateral and always located on the same side. $\mathrm{CH}$ typically begins at the back of the head, neck, and ear, and spreads over the zygomatic region. Pain associated with $\mathrm{CH}$ is sometimes throbbing. The most important feature of $\mathrm{CH}$ is that it is caused by mechanical triggers. Compression of the great occipital nerve may cause pain. Additionally, head and neck flexion, extension, and rotation may cause pain; the sensitivity and specificity of this maneuver is $91 \%$ and $90 \%$, respectively (17). The pain may begin up to $30 \mathrm{~min}$ or immediately after these maneuvers. The duration of a $\mathrm{CH}$ attack is variable and may be several days or several weeks.

The pathophysiological mechanism of $\mathrm{CH}$ is thought to be related to the trigeminocervical nucleus, which is located at the C1-C3 level $(18,19)$. Any kind of direct or indirect effects on the great and small occipital nerves might cause cervicogenic pain, yet, despite surgical evidence, this is not a fully proven theory. All structures associated with the trigeminocervical nucleus may cause $\mathrm{CH}(18,19)$.

Simple analgesics, ergotamine, oxygen inhalation, triptans, amitriptyline, botulinum toxin type A (BoNTA), sterile water, nerve blockades, epidural blockade, steroids, and surgical procedures have been used as treatment for $\mathrm{CH}$ (20-29). A few studies have assessed the usefulness of BoNTA treatment for $\mathrm{CH}$. Studies have reported variable findings concerning the usefulness of BoNTA for the treatment of $\mathrm{CH}$ (30). One of the most important findings was obtained in a placebo-controlled study that included 33 patients with $\mathrm{CH}$; analgesic use and duration of pain were found to be decreased in the BoNTA group, as compared to the placebo group (31). The present study aimed to investigate the effectiveness of BoNTA in the treatment of $\mathrm{CH}$ by comparing a placebo group 
Table 1. Dose of BoNTA (Botulinum Neurotoxin Type-A) and injection muscles

\begin{tabular}{|lccccc|}
\hline Muscles & Frontal & Temporal & Semispinalis & Splenius Capitis & Trapezius \\
\hline Total BoNTA Dose $(U)$ & 20 & 40 & 30 & 30 & 30 \\
Number of Injections & 2 & 2 & 2 & 2 & 2 \\
\hline
\end{tabular}

Table 2. Patient characteristics

\begin{tabular}{|lccc|}
\hline & BoNTA & Placebo & $\mathbf{p}$ \\
\hline Patients $(\mathrm{n})$ & 20 & 20 & \\
Age (years) & $40.05 \pm 11.23$ & $38.75 \pm 10.92$ & 0.892 \\
Sex (female/male) & $16 / 4$ & $17 / 3$ & 0.799 \\
\hline
\end{tabular}

and a BoNTA treatment group consisting of medically resistant $\mathrm{CH}$ patients.

\section{Material and Methods}

Patients who presented to our clinic with complaints of head and neck pain and diagnosed as $\mathrm{CH}$ were included in the study. Among these patients, those 18-65 years of age with normal general physical and neurological examination results, a $\leq 6$-month history of one-sided cervical pain radiating to the occulo-fronto-temporal region, no cervical abnormalities related to their complaints observed with MRI, no complaints of painful periods, and resistance to medical treatment were included in the BoNTA treatment group.

Patients who were treated with cervical and cranial surgery, received interventional treatment, had a diagnosis of any psychiatric disease, used antipsychotic, antidepressant, or antiepileptic drugs during the 3 months preceding the study, were receiving coagulopathy, were pregnant, had a neuromuscular disease, were responsive to medical treatment, and had previously received BoNTA treatment were excluded from the study.

The study protocol was approved by the local ethics committee and all the participants provided written informed consent. In total, 40 patients were included in the study, according to inclusion and exclusion criteria. Demographic characteristics of the patients are summarized in Table 1. Prior to receiving BoNTA treatment, all patients were evaluated for severity of pain using the Visual Analog Scale (VAS) and frequency of pain scores were recorded.

\section{Administration of BoNTA}

Patients in the BoNTA group $(n=20)$ were administered 10 $\mathrm{U}$ of BoNTA (Dysport ${ }^{\circledR}$ ) bilaterally to the frontal muscles, $20 \mathrm{U}$ to the temporal muscles, $15 \mathrm{U}$ to the semispinalis capitis, $15 \mathrm{U}$ to the splenius capitis, and $15 \mathrm{U}$ to the trapezius muscles (total: 150 units). Patients in the placebo group $(n=20)$ received $0.2 \mathrm{~mL}$ of saline administered to the same sites (Table 2). Following administration of BoNTA and saline, both groups were observed for $30 \mathrm{~min}$ for side effects. All participants were evaluated 6 and 12 weeks post treatment; side effects, VAS and frequency of pain scores were evaluated.

\section{Statistical analysis}

Statistical analysis was performed using SPSS v.16. Two groups in their pre-treatment, the frequency of the 6th and $12^{\text {th }}$ weeks, and VAS scores were evaluated using the Wilcoxon test. Comparison of the 2 groups was performed using the Mann-Whitney U test.

\section{Results}

Significant differences were not observed in age, or pretreatment pain intensity and frequency between the BoNTA and placebo groups ( $p>0.05)$. In the BoNTA group, pain intensity and frequency 6 and 12 weeks post treatment were significantly lower than pre-treatment levels (all $p<0.05$ ) (Table 3).

In the placebo group, the severity of pain 6 weeks post treatment was significantly lower than the pre-treatment level $(p=0.029)$, but there was no significant difference in the severity of pain between pre-treatment and 12 weeks post treatment $(p=0.441)$. There was no difference in the frequency of pain between 6 and 12 weeks post treatment in the placebo group ( $p=0.086$ and $p=0.496$, respectively).

The severity of pain at 6 weeks post treatment did not differ significantly between the 2 groups $(p=0.071)$, but the frequency of pain in the BoNTA group was significantly lower (both $p<0.001$ and $p<0.001$ ). The intensity and frequency of pain in the BoNT-A group were lower than in the placebo group at the second visit in the $12^{\text {th }}$ week $(p=0.006$ and $\mathrm{p}<0.001$, respectively) (Table 3 ).

All patients were carefully monitored for serious adverse effects. We did not observe any serious side effects resulting in the need to withdraw from the study. Side effects are summarized in Table 4.

\section{Discussion}

The present study's results indicate that BoNTA can be a beneficial treatment for patients with $\mathrm{CH}$. The BoNTA group had significantly lower severity and frequency of pain 6 and 12 weeks post treatment, as compared to pre-treatment levels. Despite a significant decrease in the severity of pain in the placebo group 6 weeks post treatment, there was no significant difference between pre-treatment and 12 weeks post treatment. The results show that BoNTA therapy was superior to saline.

BoNTA has been used to treat many types of headache, and some randomized, double-blind placebo-controlled studies examined the use of BoNTA as a prophylactic treatment for migraine and tension headaches. However, there are only a few case reports on BoNTA treatment for cluster headache, and overall the results have been inconsistent (32). Despite the fact that in Schnider et al.'s randomized, double-blind placebo-controlled study there was no significant difference in the severity of pain between the BoNTA and placebo groups, the duration of pain in the BoNTA group decreased (31).

Clostridium botulinum is an anaerobic bacteria which synthesizes toxins that target presynaptic proteins and block ace- 
Table 3. Pain severity and frequency

\begin{tabular}{|c|c|c|c|c|c|}
\hline & \multicolumn{2}{|c|}{ BoNTA group } & \multicolumn{2}{|c|}{ Placebo group } & $\begin{array}{c}\text { BoNTA vs. } \\
\text { Placebo groups }\end{array}$ \\
\hline & \multicolumn{2}{|c|}{ Mean $\pm S D$} & \multicolumn{2}{|c|}{ Mean \pm SD } & $p$ \\
\hline Pre-treatment & $73.50 \pm 9.04$ & & $71.50 \pm 11.70$ & & 0.660 \\
\hline 6 weeks post treatment & $48.75 \pm 17.00$ & $0.001^{\star} \alpha$ & $58.75 \pm 18.76$ & $0.029 * \alpha$ & 0.071 \\
\hline 12 weeks post treatment & $50.00 \pm 18.06$ & $0.001 * \beta$ & $66.00 \pm 15.44$ & $0.441 \beta$ & $0.006^{\star}$ \\
\hline \multicolumn{6}{|l|}{ Frequency of pain } \\
\hline Pre-treatment & $17.80 \pm 3.81$ & & $18.95 \pm 5.37$ & & 0.496 \\
\hline 6 weeks post treatment & $9.15 \pm 5.65$ & $0.001^{\star} \alpha$ & $17.45 \pm 5.46$ & $0.086 \alpha$ & $0.000 *$ \\
\hline 12 weeks post treatment & $10.55 \pm 5.78$ & $0.001 * \beta$ & $18.50 \pm 4.77$ & $0.496 \beta$ & $0.000 *$ \\
\hline
\end{tabular}

Table 4. Side effects

\begin{tabular}{|lcc|}
\hline Side effects & BoNTA group & Placebo group \\
\hline Localized pain at the & 2 & 2 \\
injection site & 2 & 1 \\
Dizziness & 1 & 1 \\
Backache & 0 & 1 \\
Stiff neck & 0 & 1 \\
Confusion & 1 & 0 \\
Neck muscle weakness & & \\
\hline
\end{tabular}

tylcholine secretion. BoNTA is a presynaptic neurotoxin that causes dose-dependent weakness or paralysis of skeletal muscles by blocking calcium-mediated release of acetylcholine in the motor nerve terminals; parasympathetic and sympathetic cholinergic synapse activity also decreases. Inhibition lasts between weeks and 3-4 months, and requires a germination for nerve function recovery. Protective (immune) resistance develops in response to long-term use (33).

It was reported that BoNTA is associated with substance $P$ release from neuronal cell cultures obtained from dorsal root ganglia of mouse embryos and CGRP release from neuronal cell cultures obtained from trigeminal ganglia (34). Subcutaneous BoNTA administration to the paws of mice significantly reduced the inflammatory response induced by subcutaneous formalin, which has an analgesic effect by blocking glutamate release from peripheral axons. Moreover, reduced activity was observed in dorsal root neurons in the spinal cord (34). The direct inhibitory effect of BoNTA on nociceptors due to inhibition of neuropeptide release might be responsible for central or peripheral pain pathway sensitization and neurotransmission. In addition to being a potent inhibitor of acetylcholine release, as BoNTA inhibits neurotransmitters and neuropeptides, it has anti-inflammatory and analgesic effects (34).

To further elucidate BoNTA's inhibitory effects on nociceptors additional research is needed. There are 4 possible mechanisms by which BoNTA decreases pain signals (34):

Normalization of muscular hyperactivity;

Normalization of excessive muscle activity;
Neuronal retrograde flow to the central nervous system (CNS);

Inhibition of neuropeptide release from nociceptors in peripheral tissues and the CNS.

Release of neuropeptides and inflammatory mediators in response to injury stimuli causes peripheral sensitization. Peripheral sensitization of the trigeminal nucleus and spinal cord causes an increase in the impulse, resulting in CNS sensitization. BoNTA directly limits peripheral sensitization via inhibition of the release of neurotransmitters that occurs after nociceptive stimulation or peripheral nerve injury, and indirectly limits central sensitization by inhibiting such neurotransmitters as glutamate and substance $P$ (35).

Most likely, a complex of mechanisms rather than a single mechanism are involved. Headaches arise from nociceptors in the occipital region of the head and neck. Myelinated A delta fibers transmit high-speed pain signals and unmyelinated $C$ fibers slow-speed burning pain signals; data in the literature are compatible with peripheral nerve/nerve root dysfunction or lesions. Ongoing neuropathic pain causes CNS sensitization and over time leads to chronic pain $(18,19)$.

Hobson and Gladish reported the efficacy of BoNTA treatment in a $\mathrm{CH}$ patient (23). There may be evidence that muscles play a role in the formation or spread of pain. Freund et al. reported a significant reduction in the frequency and severity in headaches in patients with chronic cervical pain treated with BoNTA (21). However, patients in this study had chronic pain secondary to cervical vertebrae injury. As such, these patients were reported as cervical-associated headache instead of cervicogenic headache.

The absence of clinically significant side effects in the present study indicates the reliability of BoNTA as a prophylactic treatment for $\mathrm{CH}$. The findings and doses reported herein are specific for the formula produced by Ipsen Biopharm Ltd. (UK). Differences in the results of various studies are due to many factors, such as BoNTA dose, BoNTA administration method, and patient population. According to the present results (similar to other published results), BoNTA can be an effective treatment method in patients with $\mathrm{CH}$. The results of controlled studies on patients with chronic daily headache show that BoNTA is well tolerated and effective in reducing the frequency of painful episodes and the number of painful days $(36,37)$. 
The present study has some limitations; the patients received only 1 dose of BoNTA, the same dose, and at the same sites. Larger placebo-controlled trials on BoNTA that use multiple dosing, different doses, and different administration methods are needed to more definitively demonstrate the therapeutic efficacy of BoNTA.

\section{Conflict of Interest}

No conflict of interest was declared by the authors.

\section{References}

1. Sjaastad O, Saunte C, Hovdahl H, Breivik H, Grønbaek E. "Cervicogenic" headache. An hypothesis. Cephalalgia 1983;3:249-56. [CrossRef]

2. Fredriksen TA, Hovdal H, Sjaastad O. "Cervicogenic headache": clinical manifestation. Cephalalgia 1987;7:147-60. [CrossRef]

3. IHS, Headache Classification Committee of the International Headache Society. The international Classification of headache disorders:2nd edition. Cephalalgia 2004;24:9-160.

4. Wight S, Osborne N, Breen AC. Incidence of ponticulus posterior of the atlas in migraine and cervicogenic headache. J Manipul Physiol Ther 1999;22:15-20. [CrossRef]

5. Hack G. Cervicogenic headache: new anatomical discovery provides the missing link. Chiroprac Rep 1998;12:1-3.

6. Mitchell BS, Humphreys BK, O'Sullivan E. Attachments of the ligamentum nuchae to cervical posterior spinal dura and the lateral part of the occipital bone. J Manipul Physiol Ther 1998;21:145-8.

7. Alix ME, Bates DK. A proposed etiology of cervicogenic headache: the neurophysiologic basis and anatomic relationship between the dura mater and the rectus posterior capitis minor muscle. J Manipul Physiol Ther 1999;22:534-9. [CrossRef]

8. Leone M, D'Amico D, Moschiano F, Farinotti M, Filippini G, Bussone $\mathrm{G}$. Possible identification of cervicogenic headache among patients with migraine: an analysis of 374 headaches. Headache 1995;35:461-4. [CrossRef]

9. Rothbart P. Cervicogenic headache: a pain in the neck. Can J Diagnos 1996;13:64-6.

10. Sjaastad $O$, Fredriksen TA. Cervicogenic headache: criteria, classification and epidemiology. Clin Exp Rheumatol 2000;18:3-6.

11. Nilsson $\mathrm{N}$. The prevalence of cervicogenic headache in a random population sample of 20-59 year olds. Spine 1995;20:1884-8. [CrossRef]

12. IHS, Headache Classification Committee of the International Headache Society. Classification and diagnostic criteria for headache disorders, cranial neuralgias, and facial pain. Cephalalgia 1988;8:1-96

13. Kränzlin P, Wälchli B. The concept of cervicogenic headache. Annual postgraduate course of the association of Swiss chiropractors, vol. 13. Interlaken, Switzerland: 1993.

14. Anthony M. Cervicogenic headache: prevalence and response to local steroid therapy. Clin Exp Rheumatol 2000;18:59-64.

15. Shah PA, Nafee A. Clinical profile of headache and cranial neuralgias. J Assoc Physicians India 1999;47:1072-5.

16. Bono G, Antonaci F, Ghirmai S, D'Angelo F, Berger M, Nappi G. Whiplash injuries: clinical picture and diagnostic work-up. Clin Exp Rheumatol 2000;18:23-8.

17. Oqince $M$, Hall $T$, Robinson $K$, Blackmore AM. The diagnostic validity of the cervical flexion-rotation test in $\mathrm{C} 1 / \mathrm{C} 2$ related cervicogenic headache. Man Ther 2007;12:256-62. [CrossRef]

18. Bovim G. Cervicogenic headache: Studies on clinical, anatomical and differential diagnostic factors. Tapir, Trondheim 1993.
19. Sjaastad O, Fredriksen T.A, Bono G, Nappi G. Cervicogenic Headache, Basic Consepts.European Headache Federation. Smith-Gordon, London 2003.

20. Bovim G, Berg R, Dale LG. Cervicogenic headache: anesthetic blockades of cervical nerves (C2-C5) and facet joint (C2/C3). Pain 1992;49:315-20. [CrossRef]

21. Freund BJ, Schwartz M. Treatment of chronic cervical-associated headache with botulinum toxin A: a pilot study. Headache 2000;40:231-6. [CrossRef]

22. Sand T, Bovim G, Helde G. Intracutaneous sterile water injections do not relieve pain in cervicogenic headache. Acta Neurol Scand 1992;86:526-8. [CrossRef]

23. Hobson DE, Gladish DF. Botulinum toxin injection for cervicogenic headache. Headache 1997;37:253-5. [CrossRef]

24. Whittingham W, Ellis WB, Molyneux TP. The effect of manipulation (toggle recoil technique) for headaches with upper cervical joint dysfunction: a pilot study. J Manipul Physiol Ther 1994; 17:369-75.

25. Vernon HT. Spinal manipulation and headaches of cervical origin. J Manipul Physiol Ther 1989;12:455-68.

26. Farina S, Granella F, Malferrari G, Manzoni GC. Headache and cervical spine disorders: classification and treatment with transcutaneous electrical nerve stimulation. Headache 1986;26:431-3. [CrossRef]

27. Nilsson N. A randomized controlled trial of the effect of spinal manipulation in the treatment of cervicogenic headache. J Manipul Physiol Ther 1995;18:435-40.

28. Nilsson N, Christensen HW, Hartvigsen J. The effect of spinal manipulation in the treatment of cervicogenic headache. J Manipul Physiol Ther 1997;20:326-30.

29. Howe D, Newcombe R, Wade M. Manipulation of the cervical spine a pilot study. J R Coll Gen Pract 1983;33:574-9.

30. Evers S, Rahmann A, Vollmer-Haase J, Husstedt IW. Treatment of headache with botulinum toxin A--a review according to evidence-based medicine criteria. Cephalalgia 2002;22:699-710. [CrossRef]

31. Schnider P, Moraru E, Bittner C, Vigl M, Wöber C, Maly J et al. Physical therapy and botulinum toxin type $A$ in patients with cervical associated headache according to IHS criteria: doubleblind, placebocontrolled study. Neurology 2001;56:A349.

32. Evers S. Status on the use of botulinum toxin for headache disorders. Curr Opin Neurol 2006;19:310-5.

33. Brunton LL, Lazo JS, Parker KL. Goodman \& Gilman's Tedavinin farmakolojik temeli. Süzer Ö, Akın D, Süzer AH, Dedeoğlu BD, Küçükhüseyin C. (Çevirenler) 1. Baskı, İstanbul: Nobel Matbaacılık, 2009;225-30.

34. Colhado OC, Boeing M, Ortega LB. Botulinum toxin in pain treatment.Rev Bras Anestesiol 2009;59:366-81.

35. Aoki KR. Review of a proposed mechanism for the antinociceptive action of botulinum toxin type A. Neurotoxicology 2005;26:785-93. [CrossRef]

36. Mathew NT, Frishberg BM, Gawel M, Dimitrova R, Gibson J, Turkel $C$. Botulinum toxin type $A$ (BOTOX) for the prophylactic treatment of chronic daily headache: A randomized, doubleblind, placebo-controlled trial. Headache 2005;45:293-307. [CrossRef]

37. Dodick DW, Mauskop A, Elkind AH, DeGryse R, Brin MF, Silberstein SD; BOTOX CDH Study Group. Botulinum Toxin Type A for the Prophylaxis of Chronic Daily Headache: Subgroup Analysis of Patients Not Receiving Other Prophylactic Medications: A Randomized Double-Blind, Placebo-Controlled Study. Headache 2005;45:315-24. [CrossRef] 